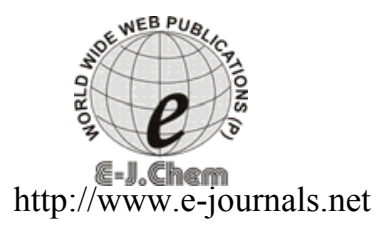

ISSN: 0973-4945; CODEN ECJHAO

E-Journal of Chemistry

2011, 8(S1), S211-S224

\title{
Synthesis and EPR Studies of Copper Metal Complexes of Dyes Derived from Remazol Red B, Procino Yellow, Fast Green FCF, Brilliant Cresyl Blue with Copper Acetate Monohydrate
}

\author{
V.DHARMALINGAM ${ }^{\S *}$, A.K.RAMASAMY ${ }^{\S}$ and V.BALASURAMANIAN \\ ${ }^{\S}$ Department of Chemistry, Periyar University Salem, Tamilnadu, India \\ Department of Chemistry \\ Environmental Science, AMET University \\ Kanathur Chennai, Tamilnadu, India \\ dharma.che@gmail.com
}

Received 28 April 2011; Accepted 3 July 2011

\begin{abstract}
The synthesis and characterization of four new solid dye complexes, $\mathrm{CuL}_{2} \quad(\mathrm{~L}=$ 2-[2-methoxy-5-(propane-1-sulfonyl)-phenyl azo]-naphthalen-1-ol, 5-\{[3-(4,6-dihydroxy-[1,3,5]tri azine-2-ylamino)-phenyl]-hydrazones $\}$-1-ethyl-4methyl-2,6-dioxo-1,2,5,6-tetrahydro-pyridine-3-carboxylic acid diethylamide, 4-\{bis-[4-(benzyl-ethyl-amino)-phenyl]-methyl $\}$-phenol and 7-imino-4-methyl$7 H$-phenoxazine-1,3-diamine) is reported. The mode for ligand coordination has been determined by IR and EPR spectra. The carboxyl and amino group of dyes coordinates to the $\mathrm{Cu}$ (II) atom as a unidentate or as a chelating ligand.
\end{abstract}

Keywords: Dyes, Copper complexes, EPR, Spectroscopy

\section{Introduction}

Reactive dye compounds are highly colored and have been used as dyes and pigments for a longtime. They have been receiving extensive attention due to many practical applications such as coloring the fibers ${ }^{1,2}$, photo electronic applications ${ }^{3}$, printing systems ${ }^{4,5}$, optical storage technology $y^{6,7}$, textile dyes ${ }^{8-}$ ${ }^{10}$ as well as in many biological reactions ${ }^{11-13}$ and also in analytical chemistry ${ }^{14,15}$. Recently metal complex dyes have also attracted increasing attention due to their increasing electronic and geometrical features in connection with their application for molecular memory storages, non linear optical elements and printing system, etc ${ }^{16}$. Therefore, several studies have been published on the synthesis and spectral properties of several dyes and metal complexes, so far ${ }^{17-25}$.

In this work, we synthesized four new solid dye-copper metal complexes by using four reactive dyes appropriate simple ligand and metal ions. The chemical structures of both dyes and metal complexes were studied. 


\section{Experimental}

All the reagents and solvent-grade quality and were used further purification.

\section{Preparation of dye solution}

The dyes used in this study are listed in Table 1 . The dyes are commercial grade and used as such without any further purification. The dyes stock solutions were prepared by dissolving accurately weighed dyes in distilled water to the concentration of $(40 \mathrm{~g} / \mathrm{L}, 20 \mathrm{~g} / \mathrm{L}, 30 \mathrm{~g} / \mathrm{L}$ and $30 \mathrm{~g} / \mathrm{L}$ ) respectively. The experimental solutions were obtained by diluting the dye stock solutions in accurate proportions to needed initial concentration.

\section{Preparation of copper acetate solution}

The cupric acetate mono hydrate used in this study was obtained from Ponmani \& Co Scientific, India. The commercial purity of copper acetate mono hydrate used without further purification. The copper acetate mono hydrate stock solution was prepared by dissolving accurately weighted copper acetate mono hydrate in distilled water to the concentration of $20 \mathrm{~g} / \mathrm{L}$. The experimental solutions were obtained by diluting the copper acetate mono hydrate stock solution in accurate proportions to needed initial concentration.

\section{Preparation of stock solution}

The stock solution of dyes and copper acetate monohydrate are listed in Table 1.

Table 1. Stock solution of dyes and copper acetate

\begin{tabular}{cccc}
\hline Trade name & $\mathrm{g} / \mathrm{L}$ & Stock solution, M & Dilution, $\mathrm{M}$ \\
\hline Remazol red B & 40 & 0.0555 & $10^{-3}$ \\
Procion yellow & 20 & 0.0572 & $10^{-3}$ \\
Fast green FCF & 30 & 0.0576 & $10^{-3}$ \\
Brilliant Cresyl Blue & 30 & 0.0640 & $10^{-3}$ \\
Copper acetate & & & \\
Monohydrate & 20 & 0.1001 & $10^{-3}$ \\
\hline
\end{tabular}

Table 2. The IR spectral data of dyes and their complexes $\left(\mathrm{KBr}, \mathrm{cm}^{-1}\right)$

\begin{tabular}{ccc}
\hline Dyes & $(\mathrm{N}=\mathrm{N})$ & Others \\
\hline Remazol red B & $1342,1418,1485$ & $3417(\mathrm{NH}), 1576(\mathrm{C}=\mathrm{N})$, \\
& & $1085(\mathrm{~N}-\mathrm{N}), 1202(\mathrm{C}-\mathrm{N})$ \\
\hline Procion yellow & 1415, & $1564(\mathrm{C}=\mathrm{N}), 1031(\mathrm{~N}=\mathrm{N})$, \\
& & $1206(\mathrm{C}-\mathrm{N}=), 2143(\mathrm{C}-\mathrm{N}=), 3355(\mathrm{NH})$ \\
\hline Fast green FCF & $1328,1410$. & $1031(\mathrm{~N}-\mathrm{N}=), 1565(\mathrm{C}=\mathrm{N})$, \\
& & $2154(\mathrm{C}-\mathrm{N}=), 3428(\mathrm{NH})$. \\
\hline Brilliant cresyl blue & 1414 & $1036(\mathrm{~N}-\mathrm{N}=), 1205(\mathrm{C}-\mathrm{N}=) 3354(\mathrm{NH})$ \\
\hline
\end{tabular}

Table 3. Absorption spectral data of dyes and their complexes

\begin{tabular}{ccc}
\hline Dyes & $\lambda_{\max }$ & $\Delta \max$ \\
\hline Remazol red B & $207.94,323.96,379.31,560.0,635.40$ & $0.99,0.75$ \\
Procion yellow & $228.39,349.97,365.00,375.98,379.96$. & $1.68,3.69$ \\
Fast green FCF & $228.01,339.34,348.08,605.42,619.68$, & $1.87,3.20$ \\
& $661.96,670.05$ & \\
Brilliant Cresyl Blue & $234.56,288.24,326.96,543.88,559.5,993.93$ & $1.15,0.26$ \\
\hline
\end{tabular}


Table 4. EPR spectral data of the dye-copper complexes at RT<smiles>CCN(Cc1ccccc1)c1ccc(C(c2ccc(O)cc2)c2ccc(N(CC)Cc3ccccc3)cc2)cc1</smiles>

Figure 1. Chemical structure of the four dyes used in this study

\section{Synthesis of dye-copper complexes}

\section{Preparation of copper-remazol red B complex}

A solution of remazole red B $(1 \mathrm{mmol}, 0.030 \mathrm{~g})$ in distilled water $(40 \mathrm{~mL})$ was added and solution of copper acetate monohydrate $(1 \mathrm{mmol}, 0.032 \mathrm{~g})$ in distilled water $(160 \mathrm{~mL})$ was added to above remazole red $B$ solution, the mixture was refluxed for $3 \mathrm{~h}$ and then $50 \mathrm{~mL}$ of water was added. The navy blue colored precipitate was filtered off, washed several times with water, dried in vacuum.

\section{Preparation of copper-procion yellow complex}

A solution of procion yellow $(1 \mathrm{mmol}, 0.014 \mathrm{~g})$ in distilled water $(40 \mathrm{~mL})$ was added and a solution of copper acetate monohydrated $(1 \mathrm{mmol}, 0.016 \mathrm{~g})$ in distilled water $(80 \mathrm{~mL})$ was added 
to above procion yellow, the mixture was refluxed for $3 \mathrm{~h}$ and then $60 \mathrm{~mL}$ of water was added. The brown colored precipitated was filtered off, washed several times with water, and dried in vacuum.

\section{Preparation of copper- fast green FCF complex}

A solution of fast green FCF $(1 \mathrm{mmol}, 0.021 \mathrm{~g})$ in distilled water $(40 \mathrm{~mL})$ was added and a solution of copper acetate monohydrated $(1 \mathrm{mmol}, .020 \mathrm{~g})$ in distilled water $(120 \mathrm{~mL})$ was added to above fast green FCF, the mixture was refluxed for $3 \mathrm{~h}$ and then $80 \mathrm{~mL}$ of water was added. The light brown colored precipitated was filtered off, washed several times with water and dried in vacuum.

\section{Preparation of copper-brilliant cresyl blue complex}

A solution of brilliant cresyl blue $(1 \mathrm{mmol}, 0.021 \mathrm{~g})$ in distilled water $(40 \mathrm{~mL})$ was added, and a solution of copper acetate monohydrated $(1 \mathrm{mmol}, 020 \mathrm{~g})$ in distilled water $(120 \mathrm{~mL})$ was added to above brilliant cresyl blue, the mixture was refluxed for $3 \mathrm{~h}$ and then $80 \mathrm{~mL}$ of water was added. The purple colored precipitated was filtered off, washed several times with water and dried in vacuum.

\section{Results and Discussion}

\section{Structural identification of dye- metal complexes}

A four new mono nuclear macro cyclic complex of dye- copper metal complexes were synthesized. FT-IR, UV-Visible and EPR spectroscopy were used to characterized the dyemetal complexes. The complexes were stable in atmosphere and polycrystalline.

\section{IR-spectra}

The IR spectra of the dyes and dye-metal complexes were recorded, the corresponding absorption intensity are present in Table 2 . The dye-metal complexes and ligand exhibits the medium intensity absorption at $1576 \mathrm{~cm}^{-1}$ which is attributable to the imines $v(C=N)^{14}$ and that absorption support the macro cyclic structure. A shift in absorption of the $v(C=N)$ frequency in case of the complexes suggests the coordination through the nitrogen $\operatorname{of}(\mathrm{C}=\mathrm{N})$ group. Moreover, another new band around $1415 \mathrm{~cm}^{-1}$ which is observed in the spectra of metal free ligands is assigned as $v(\mathrm{~N}=\mathrm{N})$. The appearance of this peak at relatively lower field may indicate co ordination via the $\mathrm{N}=\mathrm{N}$ group ${ }^{25-27}$.

\section{Absorption spectral data}

The electronic absorption spectra of the dyes and dye-metal complexes were recorded; the corresponding absorption intensity is present in Table.3. The chemical shift values $\left(\Delta \lambda_{\max }\right)$ were determined by taking the difference between the absorption maximum of the azo metal complexes with corresponding ligand. The band of shortest wavelength appearing at $228.0 \mathrm{~nm}$ may be attributed $\pi \rightarrow \pi^{*}$ transition of hetero cyclic moiety of dye compounds. The second band observed at (323.9-349.9) is attributed to $n \rightarrow \pi^{*}$ electronic transition of $-\mathrm{N}=\mathrm{N}$ - group.

In the spectra of dye-metal complexes the absorption bands in the visible region of complexes are shifted to higher wave length relative to their corresponding metal free ligands. These strong absorptions of the complexes in the near lost in the low- energy tail of the intense charge transfer transition. 


\section{EPR spectra}

The EPR spectra of dye-metal complexes were recorded, the observed g-values are present in the Table 4. The complexes exhibit anisotropic EPR spectra, recorded as polycrystalline sample at RT, which is characteristic for tetragonal $\mathrm{Cu}(\mathrm{II})$ complexes $^{20-25}$. The anisotropic $g$ values have been calculated by kneubuhl's method ${ }^{26-32}$ and by method reported earlier ${ }^{33}$. The $\mathrm{G}=\left(\mathrm{g}_{\|}-2\right) /\left(\mathrm{g}_{\perp}-2\right)$, which measure the exchange interaction between the copper centers in polycrystalline samples, have been calculated. According to Hathaway ${ }^{33-36}$, if $\mathrm{G}>4$, the exchange interaction is neglible. A value of $\mathrm{G}<4$, indicates considerable exchange interaction in the solid complexes. The calculated $G$ values are larger than four suggesting that three is no exchange interaction between the copper centers. The structures of azocopper metal complexes are shown in Figure 2.

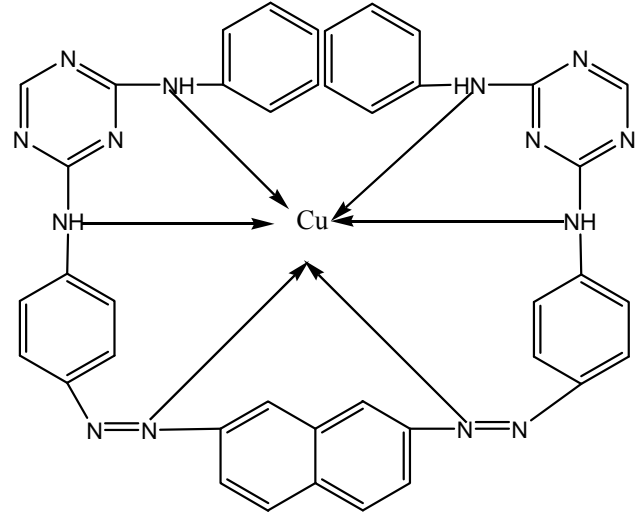

Green HE4BD-copper complex

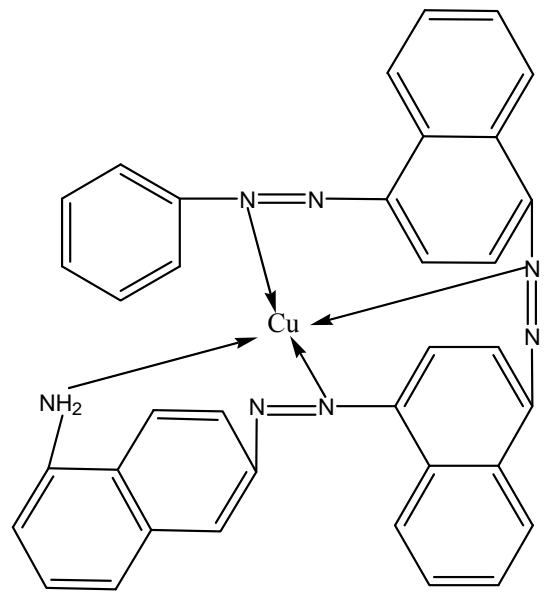

T.Blue HE5G-copper complex

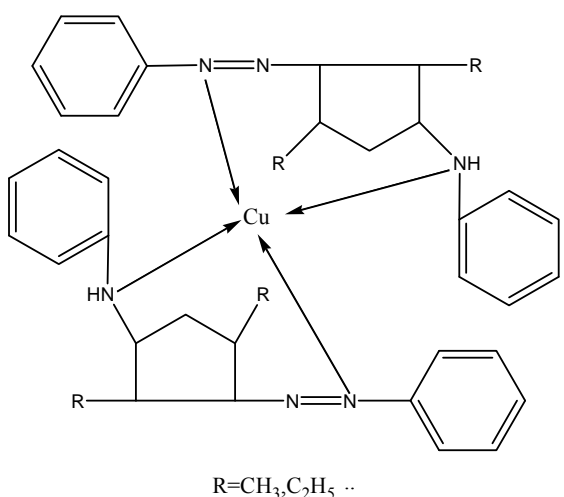

Golden yellow HER-Copper complex

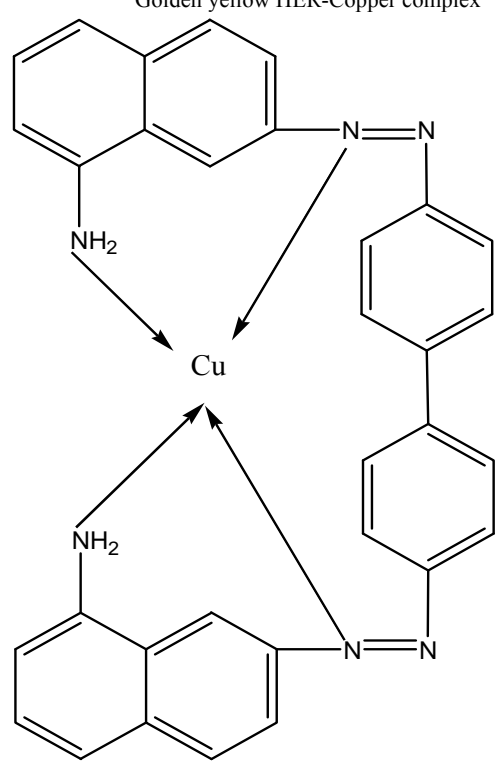

Red HE7B-copper complex

Figure 2. Structure of copper-azo dyes complexes 

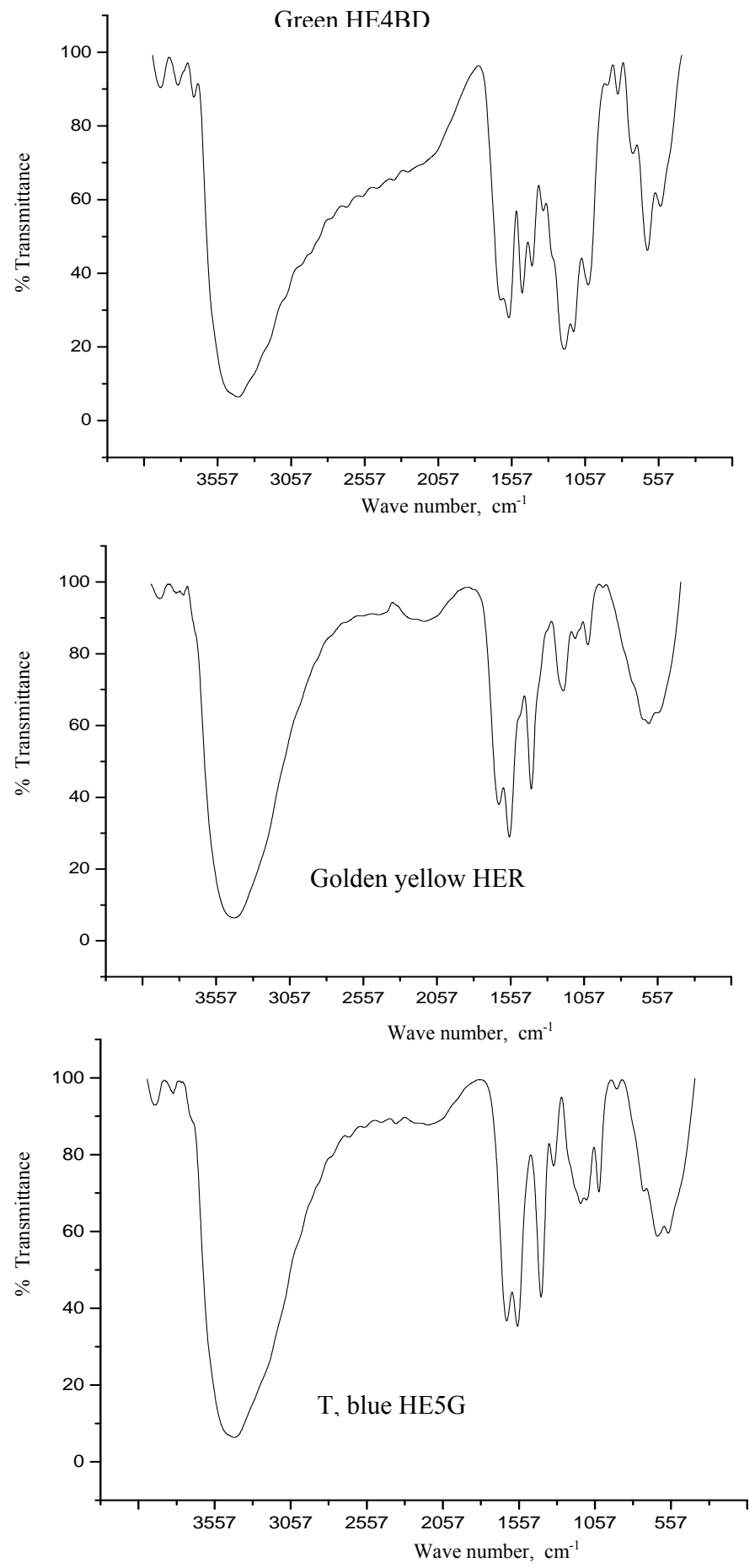

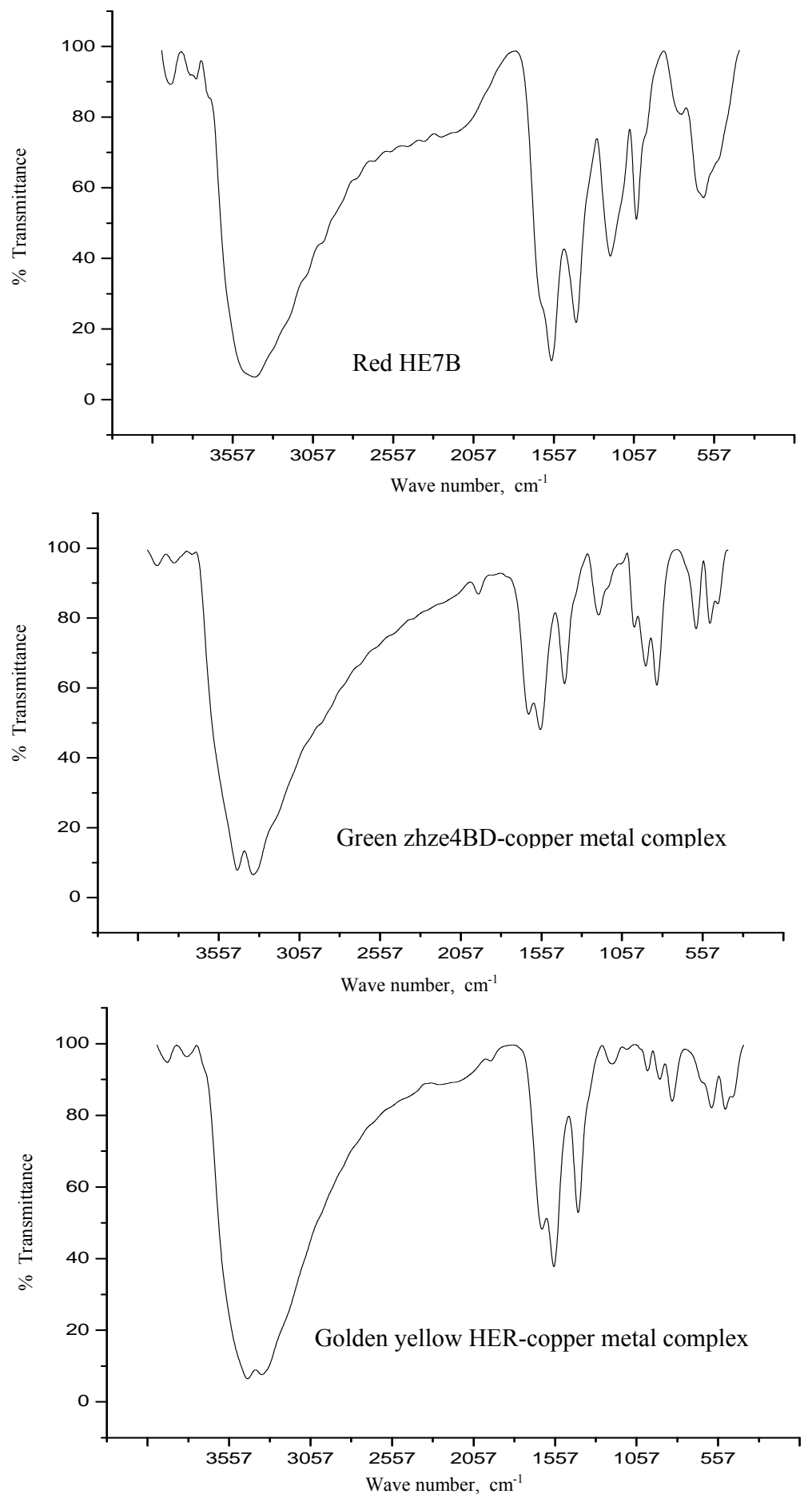

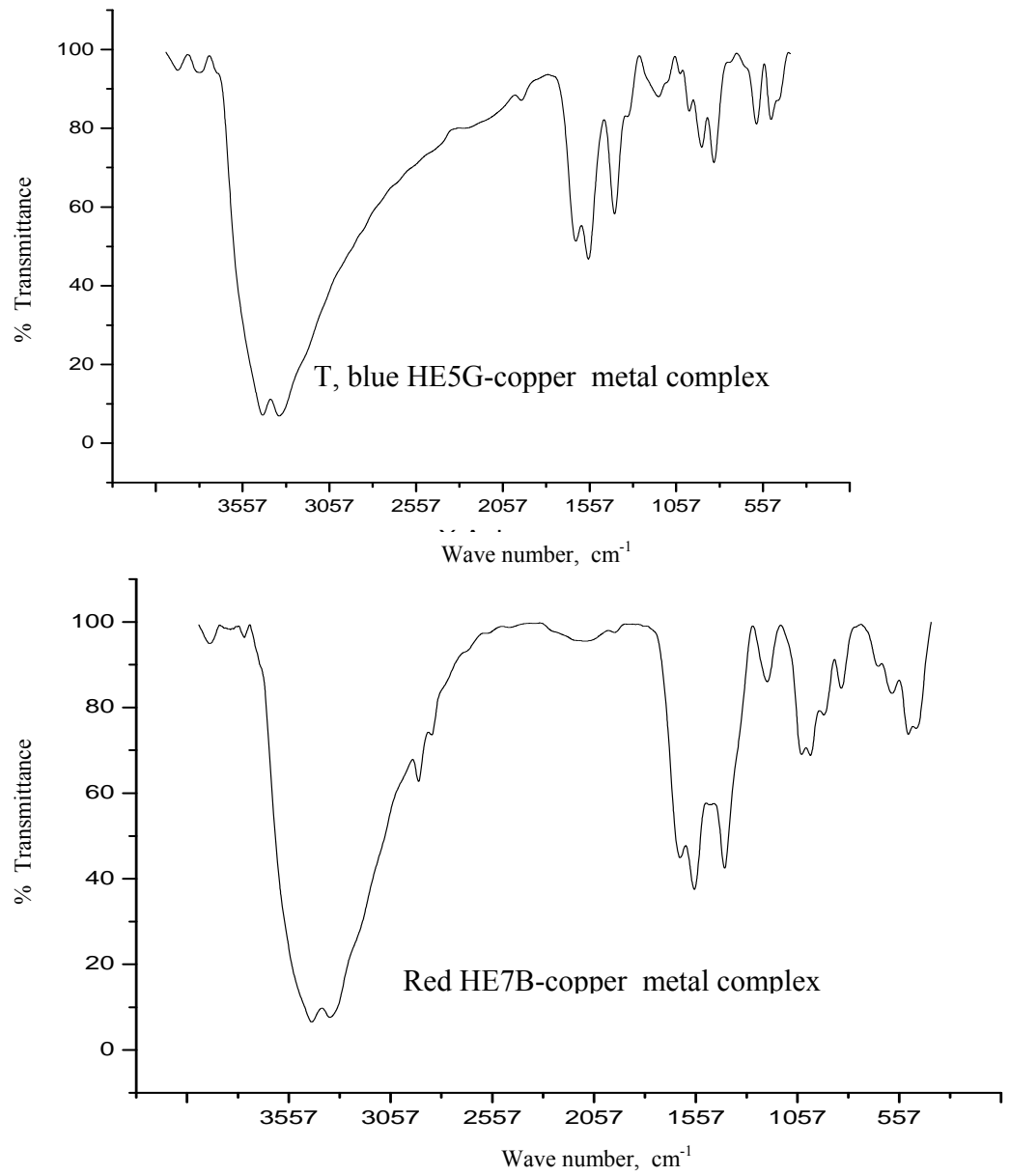

Figure 3. IR spectral data of azo dyes and azo-copper metal complexes

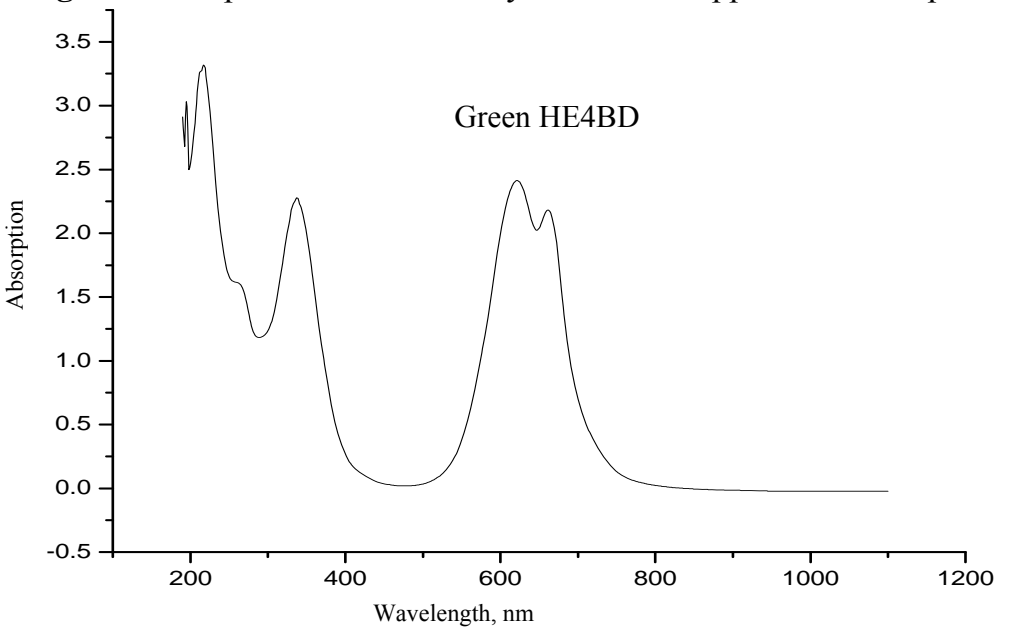



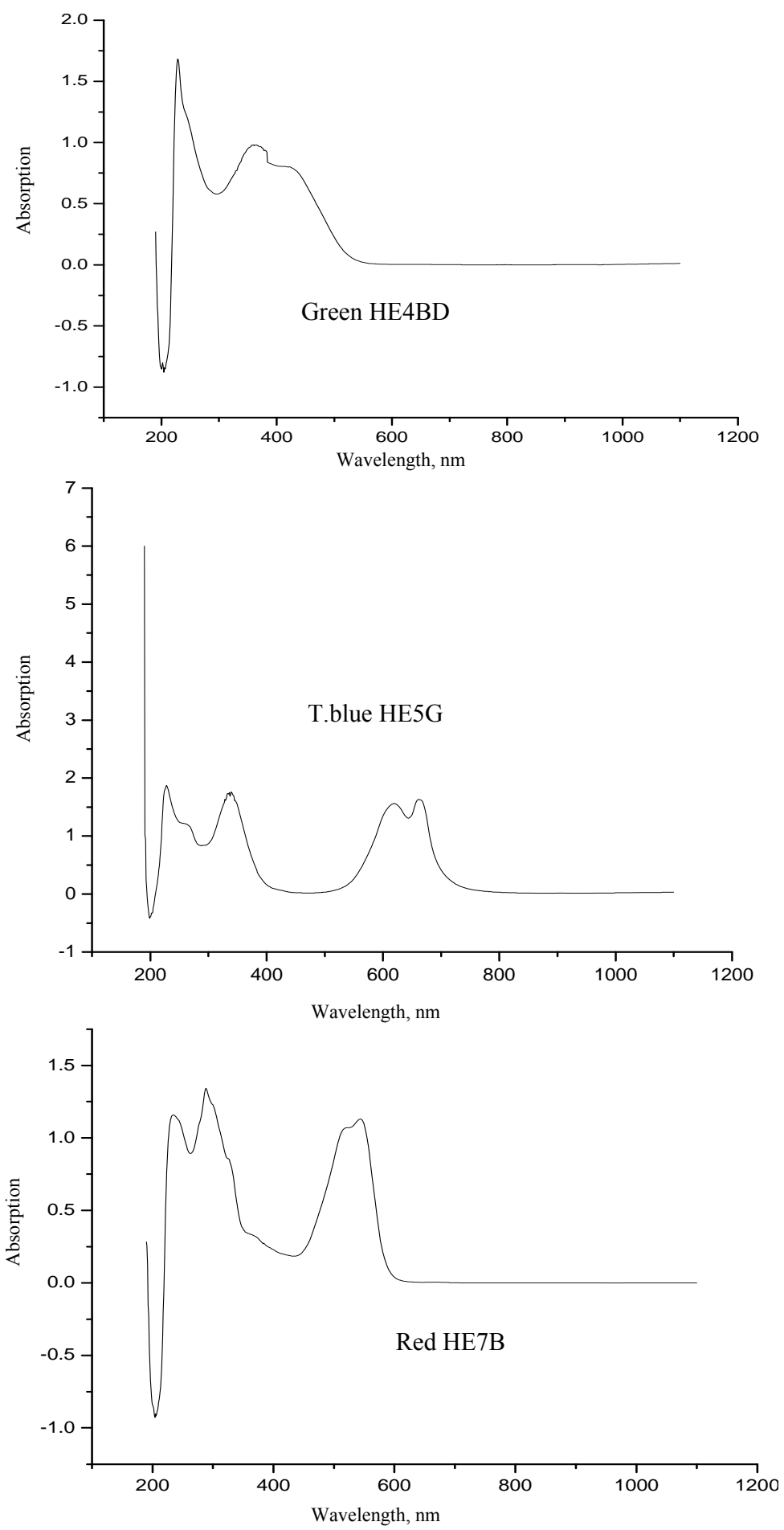

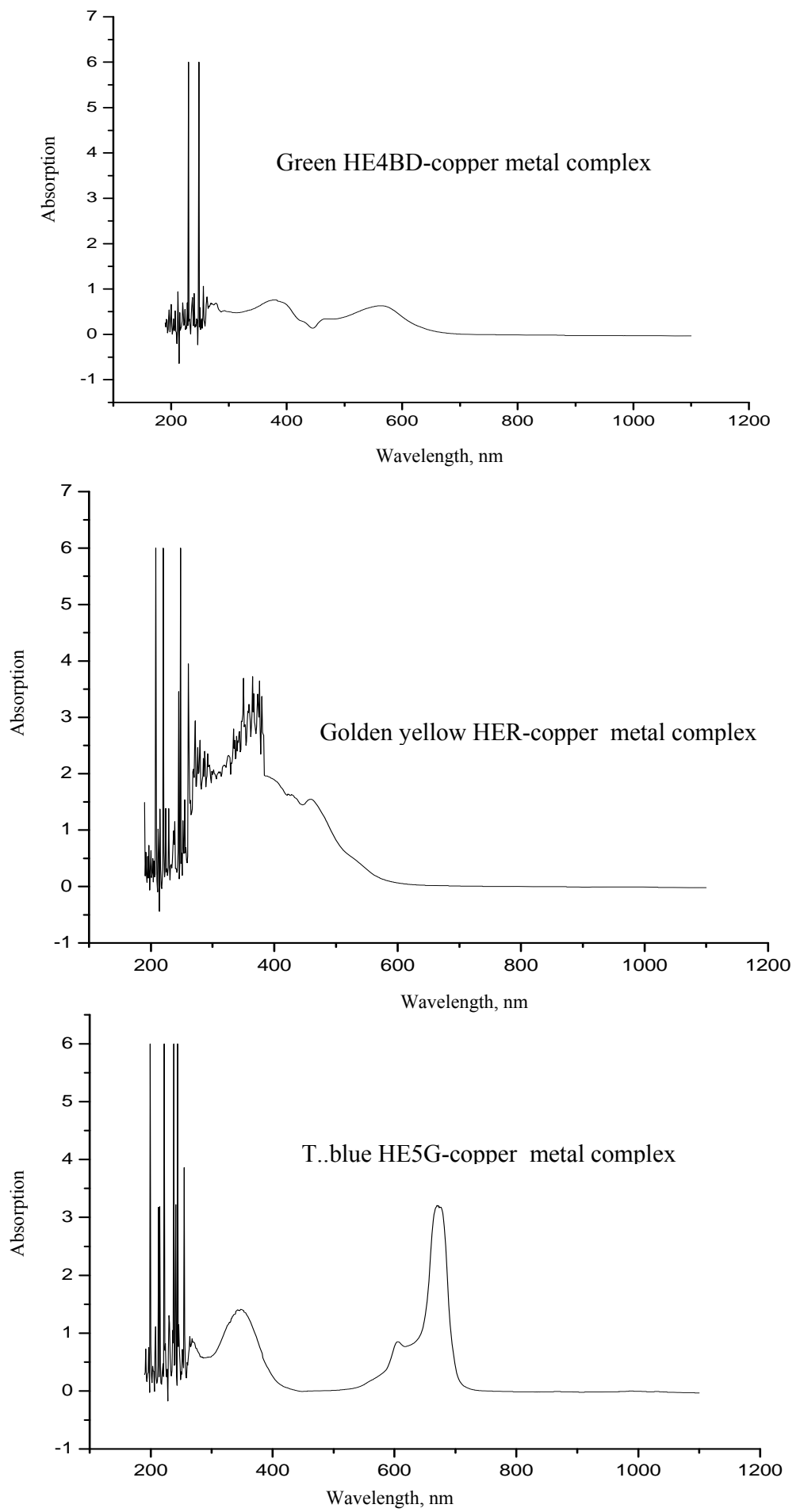


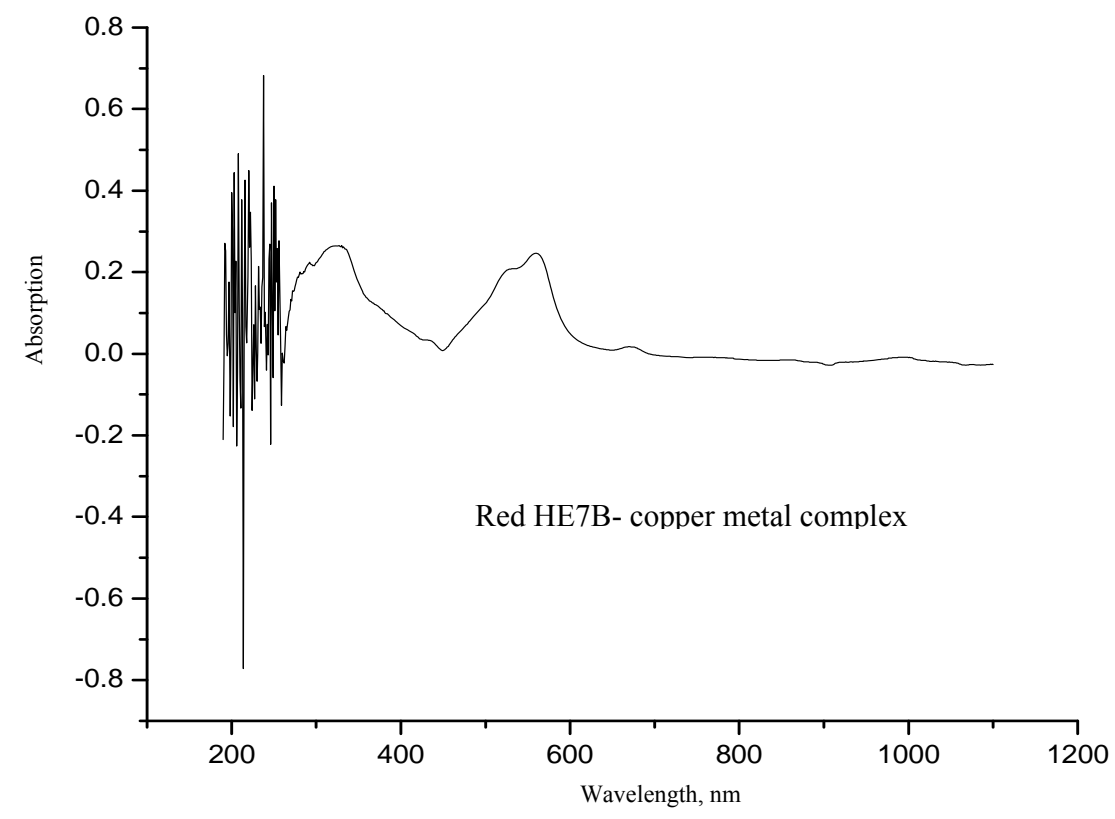

Figure 4. Absorption spectra of azo dyes and azo-copper metal complexes

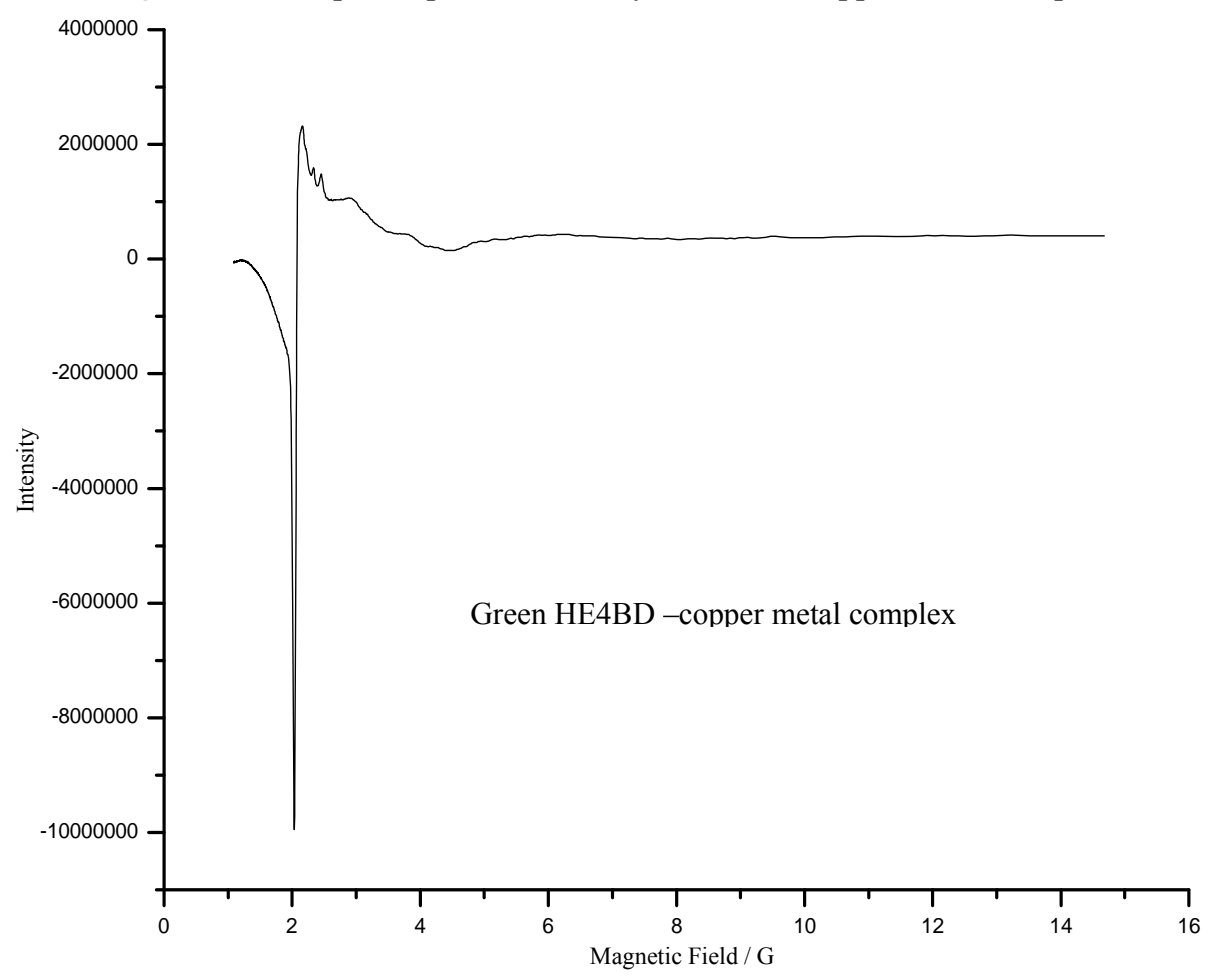



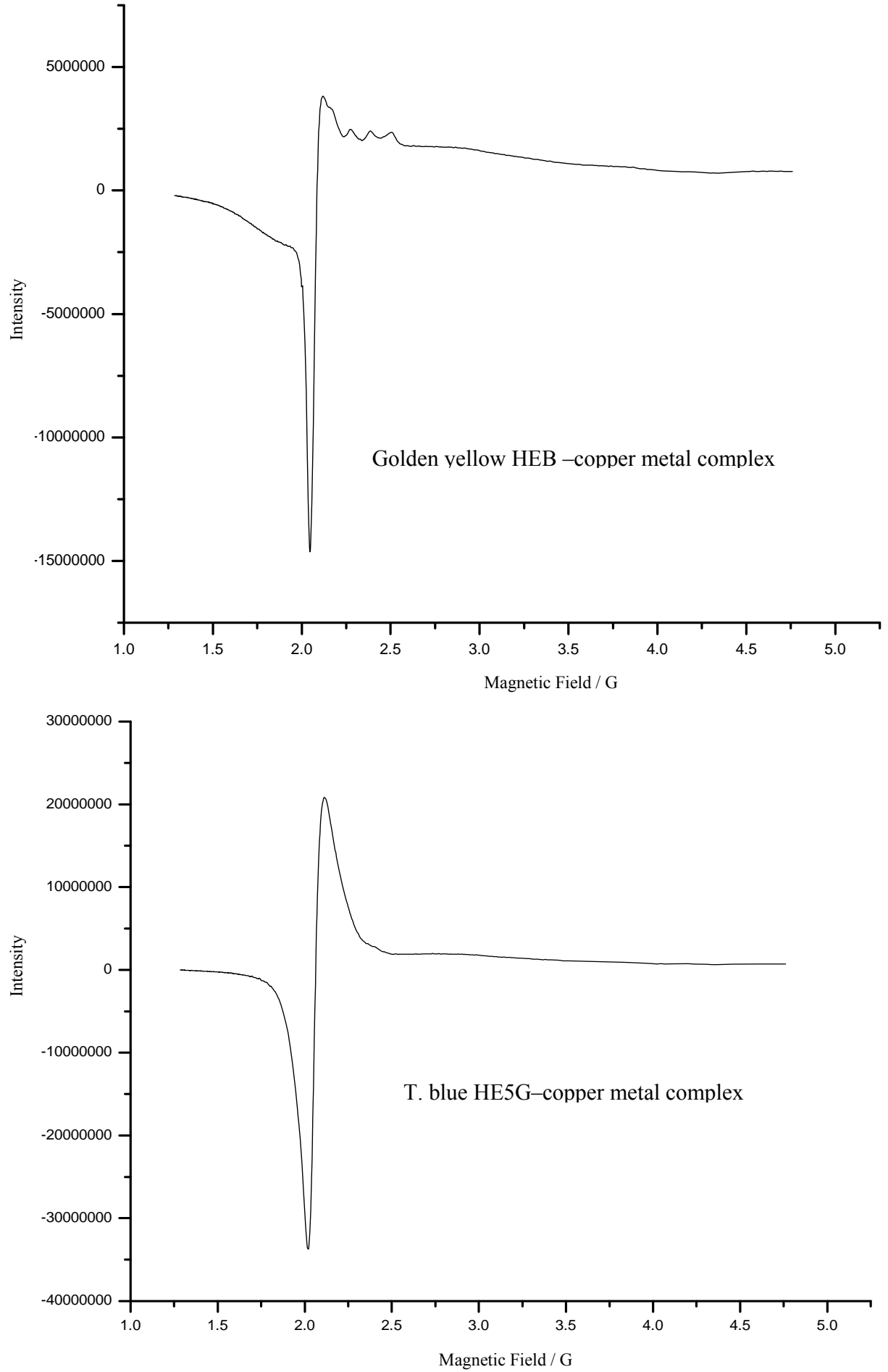


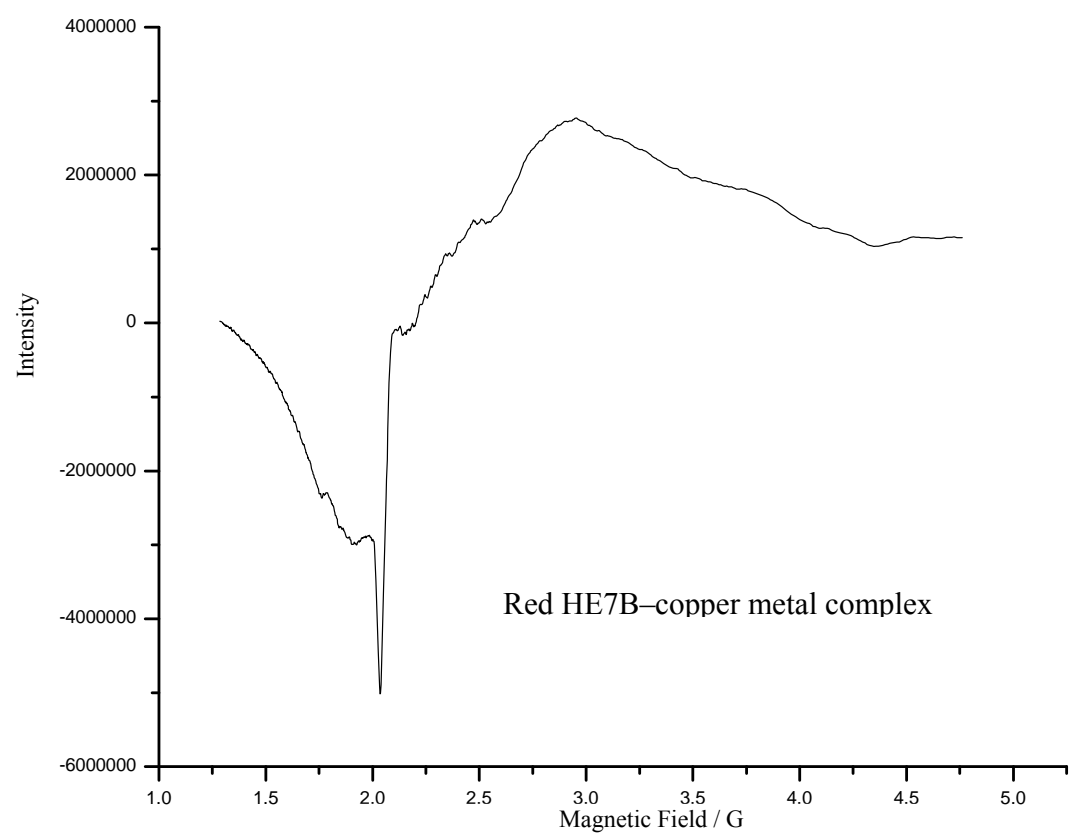

\section{Conclusion}

Figure 5. EPR spectra of azo-copper metal complexes

In conclusion, we described the synthesis and EPR studies of the four new azo-metal complexes bearing green HE4BD, golden yellow HER, T.blueHE5G, red HE7B and copper acetate monohydrate. These azo dyes exist in the form of solid state. The interaction between ligand and metal was conformed from EPR spectral values through amine and imines.

\section{Acknowledgment}

The authors are thankful to Head of the Department of Chemistry, Periyar University and AMET University for providing laboratory facility.

\section{References}

1. Koh J and Greaves A J, Dyes Pigments, 2001, 50, 13.

2. Sekar N, Colourage, 1999, 46, 63-65.

3. Katz H E, Singer K D, Sohn J E, Dirk C W, king L A, Gordon H M, J Am Chem Soc., 1987, 109(21), 6561.

4. Abe T, Mano S, Yamada Y and Tomotake A, J Imag Sci Technol., 1999, 43, 339-344.

5. Chino T and Yamada M, JP 2001220519; 2002.

6. Wang S, Shen S and Xu H, Dyes Pigments, 2000, 44, 195-198.

7. Maho K, Shintaro T, Yutaka K, Kazuo W, Toshiyuki N and Mosahiko T, Jpn J Appl Phys., 2003, 42, 1068

8. Rangnekar D W, Kanetkar V R, Malanker J V, Shankarling G S, Indian J Fibre Text Res., 1999, 24, 142-144

9. Hallas G and Choi J H, Dyes Pigments, 1999, 40(2-3), 119-129. 
10. Gregory P, Waring D R and Hallos G, editors. The Chemistry and Application of Dyes London; Plenum Press, 1990, 18.

11. Kondil S S, Transition Met Chem., 1998, 23, 461.

12. Daniel J W, Toxicol Appl Pharmacol., 1962, 4, 572-594.

13. Woisetsclager O E, Sunkel K, Weigand W and Beck W, J Organomet Chem., 1999, 584, 122-130.

14. Broekaert JAC, Anal Chim Acta, 1981, 124, 421-425.

15. Amin A S and Mohammed T Y, Talanta, 2001, 54, 611.

16. Wu S, Qian W, Xia Z, Zou Y, Wang S and Shen S, et al.Chem Phys Lett., 2000, 330, 535-540.

17. Quanli Ma, Huimin Ma, Meihong Su, Zhihca W, Lhua N and Shuchuan L, Anal Chim Acta, 2001, 439, 73.

18. Amin A S, Mohammed T Y and Mousa A A, Spectrochim Acta Part A., 2003, 59, 2577-2584.

19. Song H, Chen K and Tian H, Dyes Pigments, 2002, 53(3), 257-262.

20. Song H, Chen K, Wu D and Tian H, Dyes Pigments, 2004, 60, 111-119.

21. Adachi M, Bredow T and Jug K, Dyes Pigments, 2004, 63, 225-230.

22. Chandra R and Ghosh N N, Thermochim Acta, 1991, 189, 83-89.

23. Masound M S, Soayed A A, Ali A E anf Sharsherh O K, J Coord Chem., 2003, 56(8), 725-742.

24. Masoud M S, Mohamed G B, Abdul-Razek Y H, Ali A E and Khairy F N, J Korean Chem Soc., 2002, 46(2), 99.

25. Maiti D, Paul H, Chanda N, Chakraborty S, Mondal B, Puranik V G and Lahiri G K, Polyhedron, 2004, 23(5), 831-840.

26. Zhu Z, Kojima M and Nakajima K, Inorg Chim Acta, 2005, 358, 476-488.

27. Maiti N, Pal S and Chattopadhyay S, Inorg Chim Acta, 2001, 40, 2204.

28. Ertan N, Pal S and Chattopadyay S, Inorg Chim Acta, 2009, 49, 219.

29. Ertan N and Gurkani P, Dyes Pigments, 1997, 33(2), 137-147.

30. Sreekanth A and Kurup M R P, Polyhedron, 2003, 22, 3321.

31. Gupta R, Lal T K and Mukherjee R, Polyhedron, 2002, 21, 1245.

32. Sreekanth A, Kala U L, Nayar C R and Kurup M R P, Polyhedron, 2004, 23, 41.

33. Pilbrow J R, Transition Ion Electron Paramagneeetic Resonance, Oxford Science Publications, Oxfooorrd UK, 1990.

34. Kneubuhal F K, J Chem phys., 1960, 33, 1074.

35. Hathaway B J, in: Bradely J N and Gillard R D (Eds), Essays in Chemistry, Academic Press, New York, 1971, 2, 61-92.

36. Hathaway B J and Billing D E, Coord Chem Rev., 1970, 5, 143-207. 


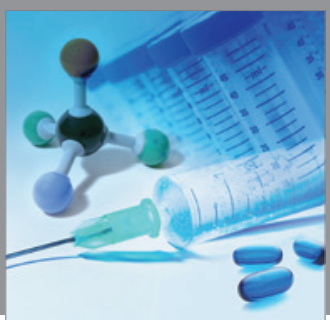

International Journal of

Medicinal Chemistry

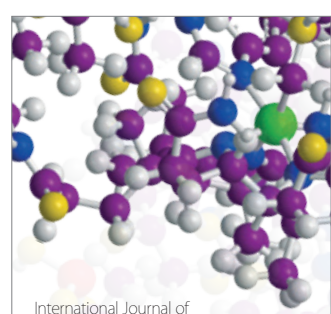

Carbohydrate Chemistry

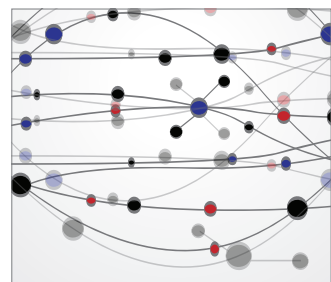

The Scientific World Journal
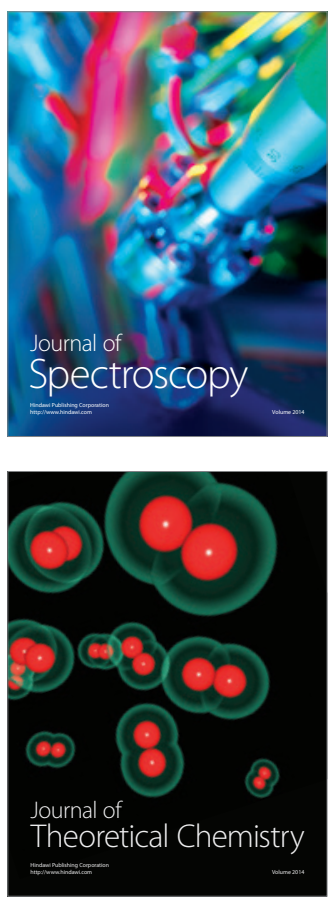
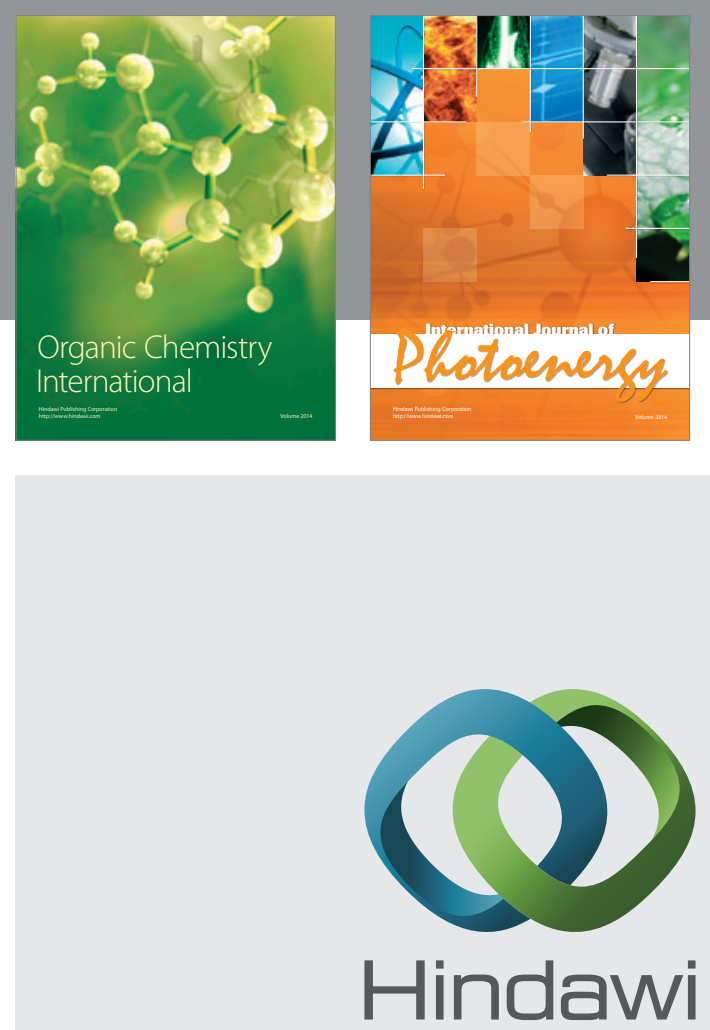

Submit your manuscripts at

http://www.hindawi.com
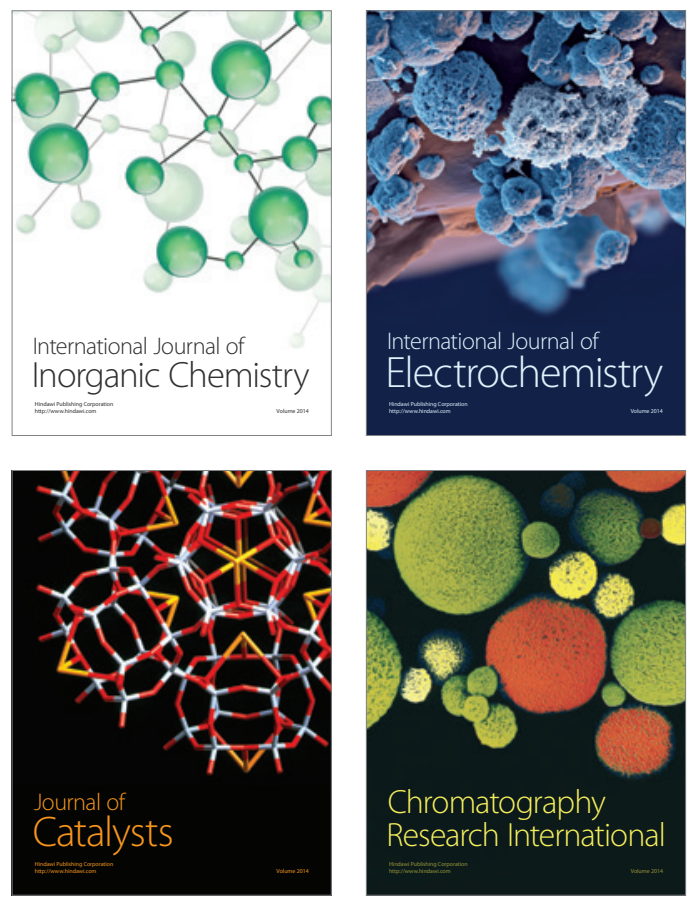
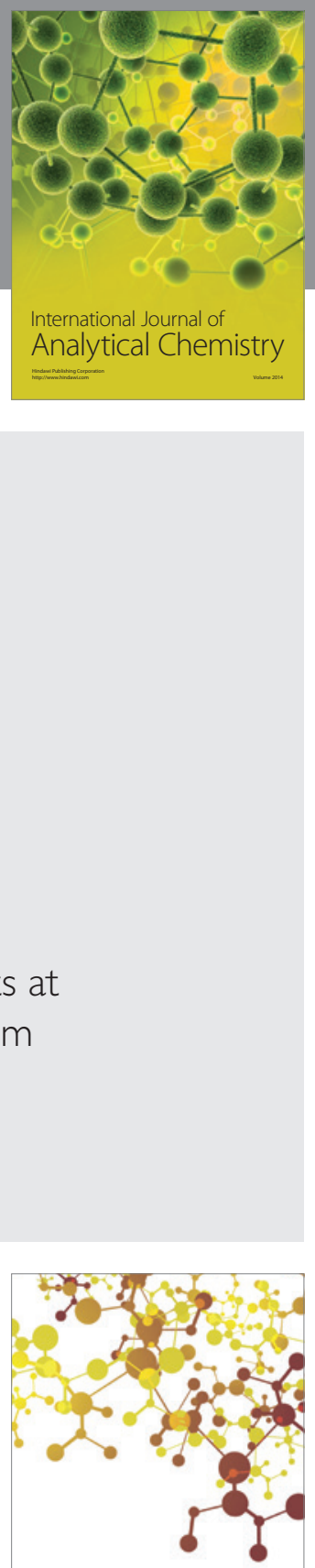

Journal of

Applied Chemistry
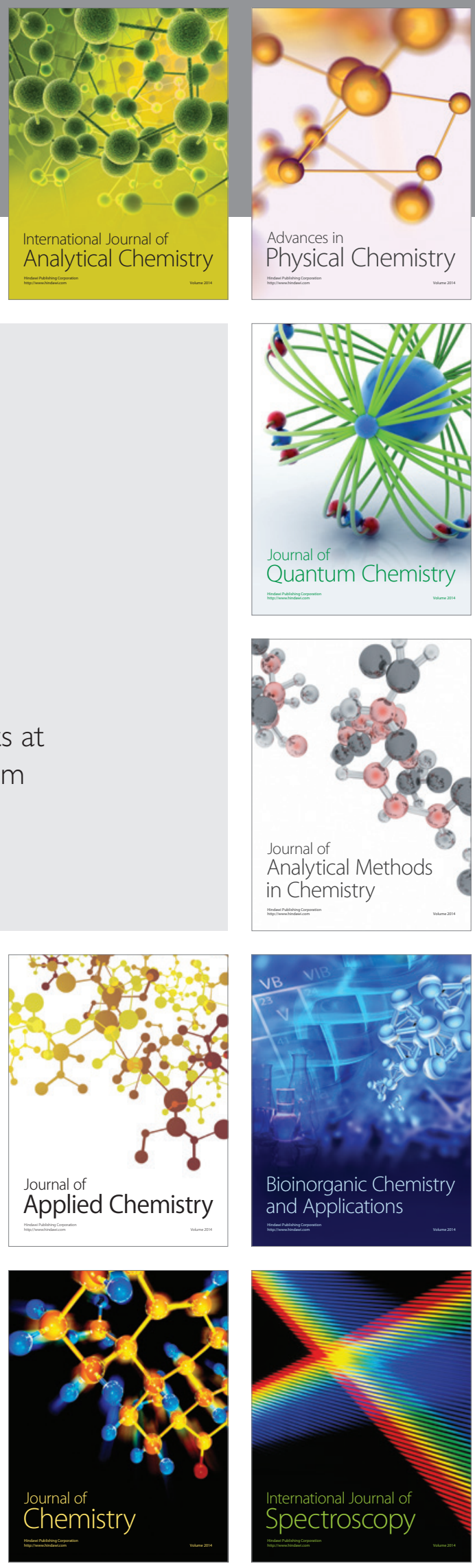